\title{
Article \\ Bioacoustic Detection of Wolves: Identifying Subspecies and Individuals by Howls
}

\author{
Hanne Lyngholm Larsen ${ }^{1, *\left(\mathbb{C}, \text { Cino Pertoldi }^{1}{ }^{(D)} \text {, Niels Madsen }\right.}{ }^{1}$, Ettore Randi ${ }^{1}$, Astrid Vik Stronen ${ }^{1,2}$, \\ Holly Root-Gutteridge ${ }^{3,4}$ and Sussie Pagh $^{1}$ \\ 1 Department of Chemistry and Bioscience, Aalborg University, 9220 Aalborg, Denmark; cp@bio.aau.dk (C.P.); \\ nm@bio.aau.dk (N.M.); erandi@bio.aau.dk (E.R.); astrid.stronen@gmail.com (A.V.S.); sup@bio.aau.dk (S.P.) \\ 2 Department of Biology, Biotechnical Faculty, University of Ljubljana, 1000 Ljubljana, Slovenia \\ 3 Animal Behaviour, Cognition and Welfare Group, University of Lincoln, Lincoln LN6 7TS, UK; \\ hrootgutteridge@lincoln.ac.uk \\ 4 School of Animal Rural and Environmental Sciences, Nottingham Trent University, Southwell NG25 0QF, UK \\ * Correspondence: hannell@bio.aau.dk
}

Citation: Larsen, H.L.; Pertoldi, C.; Madsen, N.; Randi, E.; Stronen, A.V.; Root-Gutteridge, H.; Pagh, S. Bioacoustic Detection of Wolves: Identifying Subspecies and Individuals by Howls. Animals 2022, 12, 631. https://doi.org/10.3390/ ani12050631

Academic Editor: Yikweon Jang

Received: 24 January 2022

Accepted: 28 February 2022

Published: 2 March 2022

Publisher's Note: MDPI stays neutral with regard to jurisdictional claims in published maps and institutional affiliations.

Copyright: (C) 2022 by the authors. Licensee MDPI, Basel, Switzerland. This article is an open access article distributed under the terms and conditions of the Creative Commons Attribution (CC BY) license (https:// creativecommons.org/licenses/by/ $4.0 /)$.
Simple Summary: This study evaluates the use of acoustic devices as a method to monitor wolves by analyzing different variables extracted from wolf howls. By analyzing the wolf howls, we focused on identifying individual wolves, subspecies. We analyzed 170 howls from 16 individuals from the three subspecies: Arctic wolves (Canis lupus arctos), Eurasian wolves (C.l. lupus), and Northwestern wolves (C.l. occidentalis). We assessed the potential for individual recognition and recognition of three subspecies: Arctic, Eurasian, and Northwestern wolves.

\begin{abstract}
Wolves (Canis lupus) are generally monitored by visual observations, camera traps, and DNA traces. In this study, we evaluated acoustic monitoring of wolf howls as a method for monitoring wolves, which may permit detection of wolves across longer distances than that permitted by camera traps. We analyzed acoustic data of wolves' howls collected from both wild and captive ones. The analysis focused on individual and subspecies recognition. Furthermore, we aimed to determine the usefulness of acoustic monitoring in the field given the limited data for Eurasian wolves. We analyzed 170 howls from 16 individual wolves from 3 subspecies: Arctic (Canis lupus arctos), Eurasian (C. l. lupus), and Northwestern wolves (C. l. occidentalis). Variables from the fundamental frequency (f0) (lowest frequency band of a sound signal) were extracted and used in discriminant analysis, classification matrix, and pairwise post-hoc Hotelling test. The results indicated that Arctic and Eurasian wolves had subspecies identifiable calls, while Northwestern wolves did not, though this sample size was small. Identification on an individual level was successful for all subspecies. Individuals were correctly classified with $80 \%-100 \%$ accuracy, using discriminant function analysis. Our findings suggest acoustic monitoring could be a valuable and cost-effective tool that complements camera traps, by improving long-distance detection of wolves.
\end{abstract}

Keywords: bioacoustics; Canis lupus; discriminant analysis; habitats directive; monitoring; fundamental frequency; acoustic variables

\section{Introduction}

In 2012, a wolf (Canis lupus lupus) was found dead in northern Jutland, Denmark, which was the first observation of wolves in Denmark since 1813 [1]. The wolves in Denmark are dispersers from Germany and their descendants, and are part of a connected Central European wolf population. In Europe (excluding Russia), there are more than 17,000 wolves [2]. In the European Union (EU), the wolf population is estimated to exceed 13,000 individuals [2] and the European populations are generally increasing in size due to recent protection. However, in most Western European countries the populations are still relatively small with less than 1000 wolves [1,2]. In Scandinavia, the population is 
approximately 480 wolves [3], and there are at least a further 780 individuals found in Germany and western Poland [2]. Wolves dispersing from the Central European population have reached Belgium, the Netherlands, and Denmark [1,2]. The number of wolves present in Denmark was estimated as a litter of 4 pups and 11 adult individuals in the period 1 April to 30 June 2021; in total, it was estimated that there were eight immigrant adults and seven Danish born individuals [4]. However, monitoring the population and dispersal of individuals has proved to be challenging as wolves are both wide-ranging $[5,6]$ and notoriously fearful of humans [7].

As in the rest of Europe, Denmark is obligated to monitor wolves according to the EU Habitats Directive (92/43/EEC) [8]. In Scandinavia and Germany, databases containing validated wolf observations, reported by citizens and by volunteers, and DNA samples obtained from scats and the carcasses of killed domestic animals have been established to track the population status of wolves [9-11]. A genetic reference database for wolves in Central Europe has been established to analyze the origin and movements of wolves across Europe [12].

Currently there is both active and passive monitoring of wolves in Denmark [1,13]. Active monitoring consists of registering tracks and DNA profiles, and the use of camera traps [14,15]. Passive monitoring is the registration of public observations, including organized volunteers as part of citizen science projects $[14,15]$. Camera traps are an essential tool but are limited by their small field of view compared to wolves' extensive physical range, and their effective deployment requires prior knowledge of wolf presence in an area.

Acoustic monitoring is a passive monitoring tool that has been used in the last decades for studies of diverse taxa, including insects [16], bats [17,18], birds [19], whales [20,21], and large terrestrial mammals such as ungulates [22,23] and elephants [24], and with acoustic devices; it is similarly possible to detect elusive but vocal species such as wolves [25]. Recognizing individual wolves on their howls can give insight into their movements and territory size. Several studies have shown that acoustic monitoring of wolves can be a useful and relevant tool since it is cost-effective and non-invasive [26-30] and can help recognize wolves from a distance and determine the number of wolves present [25,28,30-32].

Acoustic monitoring of wolves is based in detection of their howls [26,33,34]. Wolves use howls for different purposes: (1) to defend their territory [26,33,35], (2) to contact members of the pack $[26,35]$, and (3) to socialize [33,35]. They may howl solo or in chorus from packs [26,36]. Wolves usually howl around twilight and in the middle of the night [35] and their emissions are most intense during the months of July through October, when the presence of pups increases the pack's howling [33]. This is likely to make other predators aware that the pups are protected by adults [33].

The fundamental frequency (f0) is the lowest frequency band of the tonal call as wolf howl. For wolves, the f0 typically has values between 150 and $780 \mathrm{~Hz}$ [37] and has been used to identify individual wolves with high accuracy within subspecies of wolves such as Eastern wolves (Canis lupus lycaon) [27,38], Indian wolves (C.l. pallipes) [39], and Iberian wolves (C.l. signatus) [36]. Root-Gutteridge et al. [40] were able to identify individuals in captive Eastern wolves with 100\% accuracy using both $\mathrm{f} 0$ and amplitude (the highest variation of a wave in air pressure, perceived as volume). The use of amplitude for encoding individual identity for wolves in situ requires additional studies to determine the rate of sound suppression over distance, in different weather conditions, and through different habitats such as open land or forest [27]. Furthermore, wolves have been shown to have different vocal signatures depending on the subspecies [32,41] and are group specific [42].

Monitoring based on camera traps requires individuals in near field of view, which are most efficient at $10 \mathrm{~m}$ [43], whereas acoustic recorders cover larger distances with a with a radius of $3 \mathrm{~km}$ [28]. However, development of the methodology for analyzing the acoustic data is essential for wider scale use. Because of the small population in Denmark, captive wolves located in zoos are of importance to train the algorithm to recognize wolf howls. We know numbers present and can recognize individuals in zoos. Additionally, subspecies 
are known to show variations in their howls [41]; thus, recognition should be trained on the relevant subspecies.

The primary aim of this study is to analyze acoustic data on wolves' howls collected from wild wolves and captive wolves from three subspecies Arctic (C.l. arctos), Eurasian (C.l. lupus), and Northwestern (C.l. occidentalis) wolves, including howls from both adults and infants. The analysis is focused on individual recognition and subspecies recognition. We aim to determine whether Eurasian wolf howls have the same encoding of individual identity and, thus, can potentially be used in individual tracking via bioacoustics monitoring. Furthermore, we aim to discuss the usefulness of acoustic monitoring in the field as an additional monitoring tool of wolves.

\section{Materials and Methods}

\subsection{Collection of Acoustic Data}

Data collections took place between July 2011 and April 2021 at one privately owned location in Toropets, Russia, and the UK Wolf Conservation Trust, and five different locations in Denmark. In Denmark, recordings were made in captivity at Ree Park Safari, which had seven Arctic wolves (three adults and four pups); Skandinavisk Dyrepark, which had three adult Eurasian wolves; and Givskud Zoo with seven adult Northwestern wolves. Recordings were also made in two in situ locations in Central Jutland in areas of mixed moor and forest (Table 1), known to be wolf territories. Furthermore, 47 recordings of captive Eurasian wolves were extracted from the Macaulay Sound Library and British Library Sound Archive with their permission. Full details are given in Table 1.

Table 1. Wolves included in the individual identification with source for recordings, subspecies, and number of howls.

\begin{tabular}{|c|c|c|c|c|c|}
\hline Wolf & Source & Subspecies & Scientific Name & Status & No. of Howls \\
\hline GW1 & Givskud Zoo, Denmark & Northwestern & Canis lupus occidentalis & Captive & 2 \\
\hline GW2 & Givskud Zoo, Denmark & Northwestern & Canis lupus occidentalis & Captive & 7 \\
\hline GW3 & Givskud Zoo, Denmark & Northwestern & Canis lupus occidentalis & Captive & 2 \\
\hline SK1 & Skandinavisk Dyrepark, Denmark & Eurasian & Canis lupus lupus & Captive & 6 \\
\hline SK2 & Skandinavisk Dyrepark, Denmark & Eurasian & Canis lupus lupus & Captive & 5 \\
\hline Ulf & $\begin{array}{l}\text { In the wild close to Ulfborg, Central } \\
\text { Jutland, Denmark }\end{array}$ & Eurasian & Canis lupus lupus & Wild & 13 \\
\hline BLS004 & UK Wolf Conservation Trust & Eurasian & Canis lupus lupus & Captive & 4 \\
\hline BLS010 & British Library Sound Archive & Eurasian & Canis lupus lupus & Captive & 34 \\
\hline BLS011 & British Library Sound Archive & Eurasian & Canis lupus lupus & Captive & 7 \\
\hline BLS026 & Macaulay Sound Archive & Eurasian & Canis lupus lupus & Captive & 6 \\
\hline BLS028 & Poropets, Russia & Eurasian & Canis lupus lupus & Captive & 18 \\
\hline BLS029 & UK Wolf Conservation & Eurasian & Canis lupus lupus & Captive & 4 \\
\hline WCTM & UK Wolf Conservation Trust & Arctic & Canis lupus arctos & Captive & 7 \\
\hline WCTF & UK Wolf Conservation Trust & Arctic & Canis lupus arctos & Captive & 35 \\
\hline RW1 & Ree Park Safari, Denmark & Arctic & Canis lupus arctos & Captive & 12 \\
\hline RW2 & Ree Park Safari, Denmark & Arctic & Canis lupus arctos & Captive & 8 \\
\hline
\end{tabular}

A Song Meter SM4 acoustic recorder (Wildlife Acoustics Inc., Maynard, MA, USA) was used for recordings in Denmark. The acoustic recorder had a sampling rate (digit capacity of samples per seconds of an audio recording) of $44.1 \mathrm{kHz}$ and an amplitude resolution of 16 bits (digital capacity of amplitude values possible to record for each sample). The recorder was placed on the fences toward the wolves' enclosure in the zoos and on trees in the wild in Central Jutland 1.5-2 $\mathrm{m}$ above ground. The recorder was set to auto record in 1-4 weeks from dusk till dawn (17:00-07:30) in a two-hour interval since this is the time the wolves are most active [35], and was saved in SD cards with 128 GB storage. In Givskud Zoo a portable sound amplifier Joyo JPA-863 (Joyo Technology Co., Ltd., Baoan, Shenzhen, China) was used to elicit howling. The howls were initiated by playing sounds for the wolves. Once they started howling the sound was stopped. When the wolves had calmed 
down and they no longer barked, howled, or whined another sound was played for them. This was continued for an hour with alternating sounds of ambulance sirens, church bells, and howls from a different wolf pack.

Howls obtained from the UK Wolf Trust were recorded with a UHER 4000 REPORT $\mathrm{L}$ recorder (UHER Werke, Munich, Germany). Wolves were videoed during all howling sessions and visually identified. Recordings were digitized to $44.1 \mathrm{kHz}$ and 16 bits by the UK Wolf Trust.

Howls of a wild born but captive-held wolf were recorded in Russia by Dr. Holly Root-Gutteridge in 2011. Howls were elicited with both recordings played through a laptop and loudspeaker using three howls sampled from the file "Lonesome" recorded by Dr. Fred Harrington and by live howling. The response howls were recorded using a Sennheiser K6-ME67 (Sennheiser electronic GmbH \& Co. KG, Wedemark, NI, Germany) directional long-range microphone, Light Snake USB (Soundtech, Milford, CT, USA) connecting cable, HP laptop (HP Inc., Palo Alto, CA, USA), M-Audio Microtrack portable recorder (Avisoft Bioacoustics e.K., Glienicke/Nordbahn, BB, Germany), and USB speakers to a sampling rate of $96 \mathrm{kHz}$ and 24 bits. Where possible video was also recorded using a Sanyo Xacti CG20 digital video recorder (Sanyo, Osaka, Japan).

Howls obtained from British Library Sound Archive were recorded by Dr. Erik Zimen in the 1970s [44], as reported in the notes, and were digitized by the archive to a sampling rate of $44.1 \mathrm{kHz}$ and 16 bits.

Howls obtained from Macaulay Sound Archive were recorded with UHER 4000 REPORT L recorder using a Sennheiser MKH104 condenser microphone and was digitized by Macaulay Sound Archive to a sampling rate of $44.1 \mathrm{kHz}$ and 16 bits reported in the notes. The recordings were digitized by the archive.

All recordings were saved in the file format wav.

Fundamental frequency (f0) is the rate of which periodic sounds repeat itself [45] and are defined as the rate of which vocal folds vibrate [46]. By measuring the f0 variables, it is possible to characterize the sound and make comparisons between different vocalizations.

\subsection{Call Analysis}

The software Kaleidoscope pro 5.0.0 (Wildlife Acoustics Inc., Maynard, MA, USA) was used to train algorithms to identify wolf howls in the sound files. The signal parameters were set to $100-2000 \mathrm{~Hz}, 0.5-17 \mathrm{~s}$ in duration and the maximum inter-syllables gap (determines the end of a signal) was set to 0.35 . For cluster analysis, the maximum distance from cluster center to include in output files (vocalizations detected are analyzed to determine if their similar) was set to 1.0. The maximum fast Fourier transformation (fft) (size influence the resolution of frequency over time) of 21.33 milliseconds (ms) was selected, with a maximum number of states (Hidden Markov models target size) at 12 . The maximum distance to cluster center for building clusters (controls how cluster are formed from detected signals) was selected at 0.5. Maximum clusters (limits number of clusters formed) were set at 500 . These settings were default for clustering except for the fft that was set at maximum. The detection was reviewed both by spectrogram and audio to manually assign the howls and the data were rescanned to train the software. Additional manual filtering was performed to remove cow and crow calls.

For the data collected in Denmark, Arctic, and Eurasian wolves were identified on their solo howls. Some of the wolves would howl unaccompanied for several minutes and were identified as one individual. The howls from the identified individual were compared to other single howls from the same location. Comparing spectrograms and sound it was possible to detect a difference in the fundamental frequency where one wolf from Ree Park Safari was consistently between 100 and $200 \mathrm{~Hz}$ lower than the other especially at the start of a howl. One wolf from Skandinavisk Dyrepark had a very distinct low start in their howls and made it possible to recognize. Howling Northwestern wolves were filmed and individually identified. 
It was often impossible to extract the f0 of a wolf howl in choruses as several howls from different wolves would overlap; thus, only solo howls were used for the analysis. Recordings of howls from BLS028 and BLS029 were down sampled to $44.1 \mathrm{kHz}$ and 16 bits in Audacity (Audacity Team ${ }^{\circledR}$, USA) [47] before extracting the fundamental frequencies.

Sixteen acoustic variables (Table 2) were extracted from the howls using Praat (Praat, Amsterdam, Netherlands) [48] and a customized script in MATLAB (Mathworks Inc., Nattick, MA, USA) [49] developed previously [40], where 12 variables have been used in other studies $[27,32,36,40]$. The vocal parameters were measured by extracting the fundamental frequency (f0) contour of the calls using a cross-correlation method (Sound: To Pitch (cc) time step of 0.005 s, pitch floor $75 \mathrm{~Hz}$, pitch ceiling $1200 \mathrm{~Hz}$ ) [50]. In this study variables extracted from $\mathrm{f} 0$ were used for analysis. To make sure the $\mathrm{f} 0$ contour was tracked accurately, the contour of f0 was compared to the spectrogram (Figure 1) and if necessary, tracks of background noise such as wind or bird calls was removed. Some recordings had too much background noise, making it impossible for Praat to find the f0 and these recordings were excluded from the analysis.

Table 2. Definition of acoustic variables assessed in wolf howls to investigate identification of subspecies and individual identification of wolves.

\begin{tabular}{|c|c|c|}
\hline Variable & Definition & Extracted from \\
\hline Meanf0 a,b,c & Mean of the distribution of the fundamental frequency in $\mathrm{Hz}$ & Praat \\
\hline $\operatorname{Minf0} a, b, c$ & Minimum of fundamental frequency in $\mathrm{Hz}$ & Praat \\
\hline Posminf0 ${ }^{\text {a }}$ & Position of minimum frequency (time of min/duration) & Praat \\
\hline Maxf0 a,b & Maximum frequency in $\mathrm{Hz}$ & Praat \\
\hline Posmaxf0 a & Position of maximum frequency (time of max/duration) & Praat \\
\hline Sd & Standard deviation of the mean fundamental frequency $\mathrm{Hz}$ & Praat \\
\hline $\operatorname{Cofv}{ }^{a, b}$ & Coefficient of frequency variation $((\mathrm{sd} /$ Meanf0 $) \times 100)$ & Praat \\
\hline Slope ${ }^{\mathrm{c}}$ & The mean absolute slope of the distribution of $\mathrm{f} 0$ & MATLAB \\
\hline Cofm ${ }^{a, b}$ & $\begin{array}{l}\text { Coefficient of frequency modulation } \\
\Sigma|\mathrm{f}(\mathrm{t})-\mathrm{f}(\mathrm{t}+1)| /(\mathrm{n}-1) / \text { Meanf0 } \times 100\end{array}$ & MATLAB \\
\hline Range $^{b}$ & Range of the frequency (Maxf0 - Minf0) & Praat \\
\hline Q25 & $25 \%$ of the distribution of the fundamental frequency in $\mathrm{Hz}$ & Praat \\
\hline Q75 & $75 \%$ of the distribution of the fundamental frequency in $\mathrm{Hz}$ & Praat \\
\hline IQR & Interquartile range of f0 (Q75 - Q25) & Praat \\
\hline Startf0 ${ }^{c}$ & Start of the fundamental frequency in $\mathrm{Hz}$ & MATLAB \\
\hline Endfo $a, b, c$ & End of the fundamental frequency in $\mathrm{Hz}$ & MATLAB \\
\hline Duration $\mathrm{a}, \mathrm{b}, \mathrm{c}$ & Duration of the howl in seconds & MATLAB \\
\hline
\end{tabular}

Variables used in: ${ }^{a}$ Hennelly et al., (2017) [32], ${ }^{\text {b }}$ Root-Gutteridge et al., (2014) [27], ${ }^{c}$ Watson et al., (2018) [50].

\subsection{Processing the Data}

The howls recorded in Denmark were recorded in 2020-2021. During this study period, a total of 265 solo howls were recorded. Of these howls, 89 had too much wind noise to have accurate extractions and were removed. Of the remaining 176 howls collected, only 55 howls could be assigned to individual wolves (Table 1) were retained for further analysis. In Ree Park Safari and Skandinavisk Dyrepark we identified two out of three wolves. In Givskud Zoo we identified three out of seven adult wolves. Each of the seven wolves were named after the location and in order of the onset of howling, Wolf1, Wolf2, and Wolf3 (Table 1). Further, we used 50 wolf howls collected from The UK Wolf Conservation Trust and 18 Eurasian wolf howls collected in Russia by HRG. We also used archival howls: a further 41 Eurasian wolf howls from British Library Sound Archive, 6 Eurasian wolf howls from Macaulay Sound Library, The Eurasian wolves were given the letters BLS to show they were all from the same subspecies and not collected for this study.

Each wolf had their own ID number (BLS004 had the ID number 004 etc.) The Arctic wolves were called WCT with F for female and M for male. The first three letters were used to define them as being from the same source as well as the same subspecies. 
A

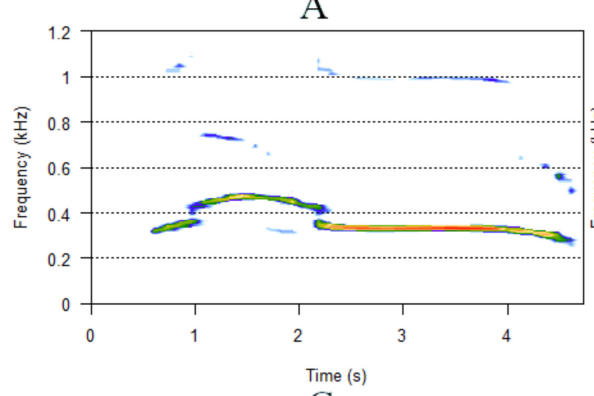

C

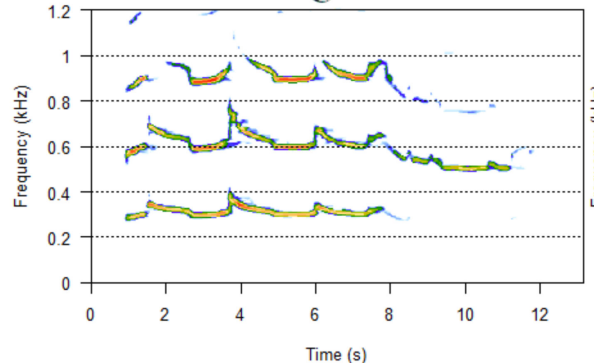

$\mathrm{B}$

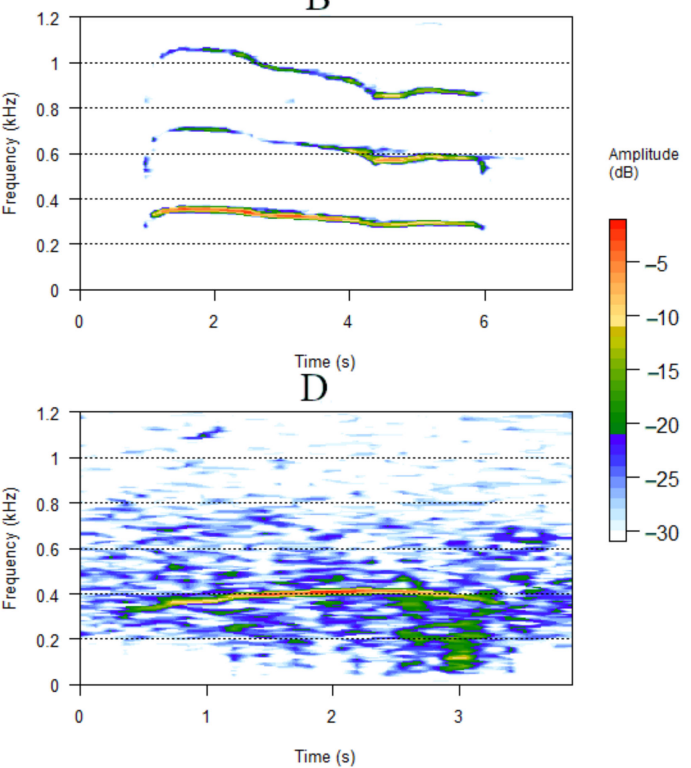

Figure 1. Example of spectrograms of single howls from (A). Northwestern wolves; (B). Arctic wolves; (C). Captive Eurasian wolves; and (D). Eurasian wolves with noise. The $y$-axis shows the frequency in $\mathrm{kHz}$ and the $x$-axis shows the time in seconds. Colors indicate the amplitude of the howls in $\mathrm{dB}$ (decibel). The lowest band in the spectrograms are the fundamental frequency (f0) and the other two are the second and third harmonic, which are visible in $(\mathbf{A}-\mathbf{C})$. The amplitude is in negative $\mathrm{dB}$ as 0 is referring to the maximum sound [51]. Graphs were made in the program RStudio [52] using the package Seewave [53].

\subsection{Identification of Subspecies}

Tests for differences in the acoustic variables were made with a one-way ANOVA and any variables with non-significant $p$-values $(p>0.05)$ were removed from further testing. Thus, the variables Minf0 and Cofv were non-significant $\left(\mathrm{F}_{\mathrm{Minf}}=5.3, p>0.05\right.$; $\left.\mathrm{F}_{\text {Cofv }}=2.5, p>0.05\right)$ and were excluded from further tests. To avoid multicollinearity, we tested for correlation (Pearson's correlation $r>0.6$ ). Meanf0 were removed as they were highly correlated with Maxf0 $(r=0.91)$ and Endf0 $(r=0.87)$. Range was removed as it was highly correlated with Maxf0 $(r=0.74)$ and standard deviation $(\mathrm{Sd})(\mathrm{r}=0.87)$. Posminf0 was highly correlated with Posmaxf0 $(r=0.59)$ and was removed.

A discriminant function analysis, hereafter discriminant analysis, was run in RStudio (RStudio, Boston, MA, USA) [52] and was applied to nine of the 16 acoustic variables (Maxf0, Posmaxf0, Sd, Slope, Cofm, IQR, Startf0, Endf0, and Duration) that were also used in studies discriminating among subspecies [32]. The discriminant analysis was applied to determine whether it is possible to correctly classify the already identified subspecies howls using these nine variables. A classification matrix was obtained to compare known howls to predicted howls. A pairwise post-hoc Hotelling test was used on the acoustic variables to test if there was a statistically significant difference between the howls in subspecies. In RStudio the datasets were randomly divided into smaller subsets making sure the number of howls were equal between all the subspecies. We ensured all the data from the large dataset were represented at least once in the subsets. This was performed as samples from different subspecies were not equal. A Sequential Bonferroni correction was applied to the pairwise post-hoc Hotelling test [54].

\subsection{Individual Identification of Wolves from Howls}

Northwestern wolves were excluded from the individual analysis as it was only possible to isolate two howls from two of the three wolves.

The same procedure for identifying subspecies was applied for individual identification. For Arctic wolves all variables were significant in the ANOVA. Pearson correlation 
showed that Meanf0 was highly correlated with Minf0 ( $r=0.74)$, Maxf0 ( $r=0.91)$ and Endf0 $(\mathrm{r}=0.83)$ and was removed. Posminf0 was highly correlated with Posmaxf0 $(\mathrm{r}=0.85)$ and was removed. Cofv was removed to ensure same variables in the analysis of both Eurasian and Arctic wolves. Slope was removed as it was highly correlated with Endf0 $(r=0.63)$. Range was removed as it was highly correlated with Maxf0 $(r=0.71)$ and Sd $(r=0.9)$. IQR was highly correlated with Startf0 $(r=0.69)$ and was removed (Table 3$)$.

Table 3. Removed variables and the variables they were correlated with from Pearson correlation test both for the analysis of Subspecies and for the analysis of individual identification within the two subspecies: Arctic and Eurasian wolves.

\begin{tabular}{lll}
\hline & Removed Variable & Correlated with \\
\hline \multirow{3}{*}{ Subspecies } & Meanf0 & Maxf0, Endf0 \\
& Range & Maxf0, Sd \\
& Posminf0 & Posmaxf0 \\
\hline \multirow{3}{*}{ Arctic wolves } & Range & Maxf0, Sd \\
& Posminf0 & Posmaxf0 \\
& Cofv & \\
& Slope & Endf0 \\
& Range & Maxf0, Sd \\
& IQR & Startf0 \\
\hline & Meanf0 & Minf0, Maxf0, Endf0 \\
Posminf0 & Minf0 \\
Cofv & Maxf0 \\
& Slope & Startf0, Endf0 \\
& Range & Minf0 \\
\hline
\end{tabular}

For Eurasian wolves all variables were significant with ANOVA. Pearson correlation showed that Meanf0 was highly correlated with Minf0 ( $r=0.9)$, Maxf0 ( $r=0.89)$, and Endf0 $(\mathrm{r}=0.89)$ and was removed. Posminf0 was removed as it was highly correlated with Minf0 $(\mathrm{r}=0.59)$. IQR was highly correlated with Minf0 $(\mathrm{r}=0.84)$ and was removed. Cofv was highly correlated with Maxf0 $(\mathrm{r}=0.72)$ and was removed. Slope was removed to ensure same variables in both analyses. Range was highly correlated with Endf0 $(r=0.71)$ and Startf0 $(r=0.62)$ and was removed (Table 3).

A discriminant analysis for was applied to eight of the 16 variables for the Arctic and Eurasian wolves (Minf0, Maxf0, Posmaxf0, Sd, Cofm, Startf0, Endf0, and Duration).

The discriminant analysis was applied to test if it was possible to correctly classify individual wolves from howls of already identified wolves within the same subspecies. A classification matrix was created to compare known howls to predicted howls. A pairwise post-hoc Hotelling test was run to test if there was a difference between the howls of individual wolves within the same subspecies. The same procedure of random subsets and sequential Bonferroni correction was applied to the identification of individual wolves.

\section{Results}

\subsection{Identification of Subspecies}

All the 170 howls from the seven wolves were used in the analysis for subspecies. The discriminant analysis using nine acoustic variables (Maxf0, Posmaxf0, Sd, Slope, Cofm, IQR, Startf0, Endf0, and Duration) gave an overall 78\% of correctly classified subspecies (Figure 2). For Northwestern wolves the classification was 64\%, for Arctic wolves, the classification was $82 \%$, and finally for Eurasian wolves it was $77 \%$. Pairwise post-hoc Hotelling test analysis showed significant difference in howls between Arctic and Eurasian wolves $(\mathrm{DF}=9, \mathrm{~F}=23.77, p<0.001)$, Arctic and Northwestern wolves $(\mathrm{DF}=9, \mathrm{~F}=2.9$, $p<0.01)$, and Eurasian and Northwestern wolves ( $\mathrm{DF}=9, \mathrm{~F}=10, p<0.001)$ all $p$-values were significant after sequential Bonferroni correction (Table 4). The randomized subsets 
gave overall correct classifications between $70 \%$ and $90 \%$ where most were between $82 \%$ and $88 \%$. Pairwise post-hoc Hotelling test showed significant differences between most randomized subsets. After sequential Bonferroni $72 \%$ was not significant.

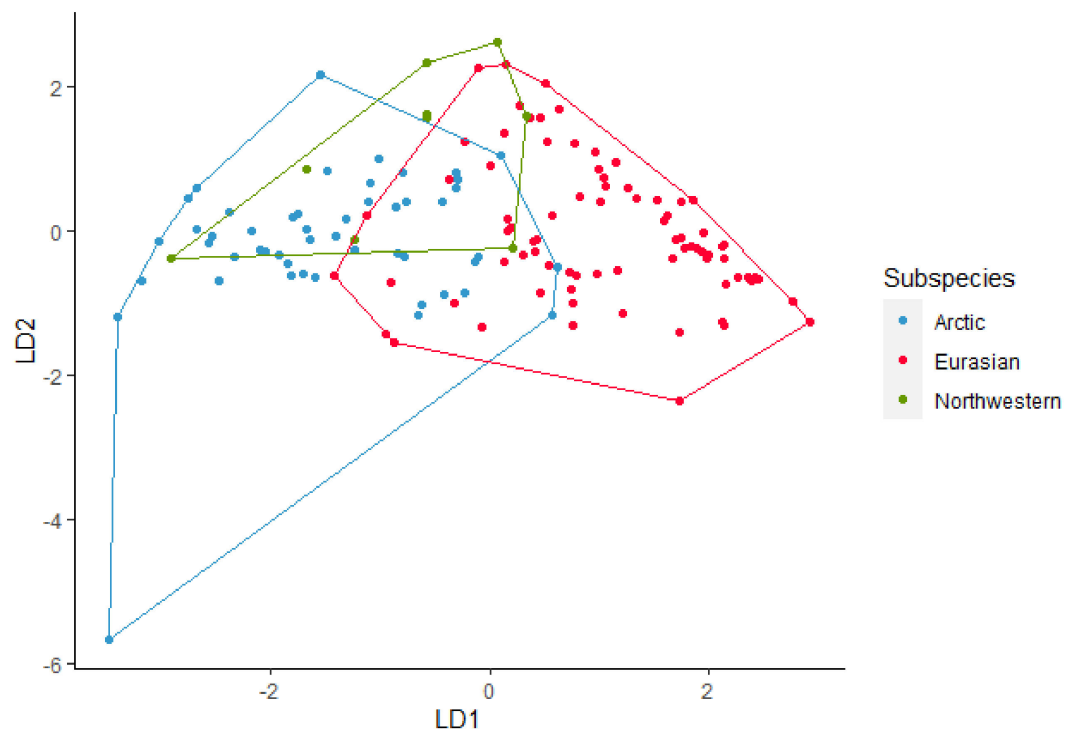

Figure 2. Linear discriminant (LD) analysis plot for identification of the subspecies Arctic, Eurasian, and Northwestern wolves with a 78\% correct classification.

Table 4. Pairwise post-hoc Hotelling test for Subspecies with F-values, $p$-values, and number of degrees of freedom (DF). Symbol \# indicates significant $p$-values after sequential Bonferroni.

\begin{tabular}{cccc}
\hline & F & $p$ & DF \\
\hline Arctic-Eurasian & 23.77 & $<0.001^{\#}$ & 9 \\
Arctic-Northwestern & 2.9 & $<0.01^{\#}$ & 9 \\
Eurasian-Northwestern & 10 & $<0.001^{\#}$ & 9 \\
\hline
\end{tabular}

\subsection{Individual Identification of Arctic Wolves}

Sixty-two howls from four wolves were used in the analysis of howls from Arctic wolves. The discriminant analysis using eight variables (Minf0, Maxf0, Posmaxf0, Sd, Cofm, Startf0, Endf0, and Duration) gave an overall 95\% correct classification of howls from the four wolves (Figure 3). Classification of each wolf showed that RW1, RW2 and WCTM all have $100 \%$ correct classification and WCTF has a $91 \%$ correct classification. The pairwise post-hoc Hotelling test showed significant difference in howls between RW1 and RW2 (DF = 8, F = 33.2, $p<0.001)$, between howls from RW1 and WCTM (DF = 8, F = 37.52, $p<0.001)$, between RW2 and WCTM (DF $=8, \mathrm{~F}=9.68, p<0.01)$, between RW1 and WCTF $(\mathrm{DF}=8, \mathrm{~F}=93,87, p<0.001)$, between RW2 and WCTF $(\mathrm{DF}=8, \mathrm{~F}=41.74, p<0.001)$ and lastly between WCTM and WCTF $(\mathrm{DF}=8, \mathrm{~F}=8.2, p<0.01)$. All pairwise post-hoc Hotelling tests showed significant differences after sequential Bonferroni were applied (Table 5). After randomizing the data, the correct classification ranged between $89 \%$ and $100 \%$, where most lay between $94 \%$ and $97 \%$. The pairwise post-hoc Hotelling tests for the randomized subsets showed significant differences with all subsets of RW1 after sequential Bonferroni correction. The pairwise post-hoc Hotelling test showed significant differences between RW2 and WCTM. However, after sequential Bonferroni correction 70\% was not significant. The pairwise post-hoc pairwise post-hoc Hotelling tests for randomized RW2 and WCTF showed significant difference in howls for all subsets. After sequential Bonferroni correction $80 \%$ was significant. The pairwise post-hoc Hotelling for randomized WCTM and WCTF showed significant differences for most subsets. After sequential Bonferroni correction $70 \%$ was not significant. 


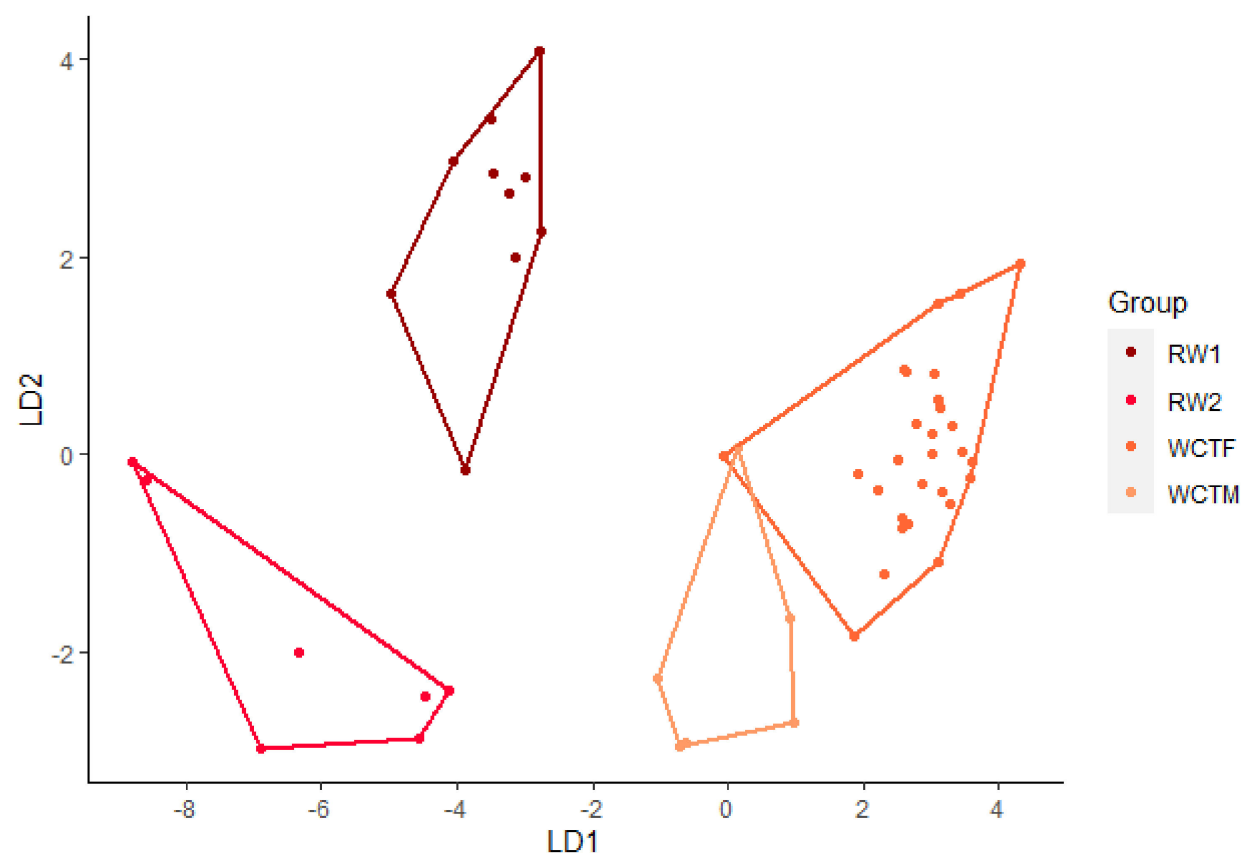

Figure 3. Linear discriminant (LD) analysis plot for individual identification of howls from Arctic wolves with a $95 \%$ correct classification.

Table 5. Pairwise post-hoc Hotelling test for Arctic wolves with F-values and $p$-values. Symbol \# indicates significant $p$-values after sequential Bonferroni test.

\begin{tabular}{cccc}
\hline & F & $p$ & DF \\
\hline RW1-RW2 & 33.2 & $<0.001^{\#}$ & 8 \\
RW1-WCTM & 37.52 & $<0.001^{\#}$ & 8 \\
RW1-WTCF & 93.87 & $<0.001^{\#}$ & 8 \\
RW2-WCTM & 9.68 & $<0.01^{\#}$ & 8 \\
RW2-WCTF & 41.74 & $<0.001^{\#}$ & 8 \\
WCTM-WCTF & 8.2 & $<0.01^{\#}$ & 8 \\
\hline
\end{tabular}

\subsection{Individual Identification of Eurasian Wolves}

Ninety-seven howls from nine Eurasian wolves were used in this analysis. Using eight variables (Minf0, Maxf0, Posmaxf0, Sd, Cofm, Startf0, Endf0, and Duration), the discriminant analysis achieved $89 \%$ accurate classification (Figure 4). SK1, and ULF achieved $100 \%$ correct classification. BLS0028 achieved a correct classification of $94 \%$, BLS011 had an $85 \%$ correct classification. BLS026 achieved 83\% correct classification and BLS010 achieved an $82 \%$ correct classification. The pairwise post-hoc Hotelling test showed significant differences between howls from all except BLS011 and BLS026 (Table 6). After sequential Bonferroni correction BLS026 and SK1 and BLS011 and SK1 were not significant. After randomizing the data, the correct classification ranged between $89 \%$ and $97 \%$, where most were between $92 \%$ and $97 \%$. The pairwise post-hoc Hotelling test revealed $57 \%$ significant differences and 20\% was significant after sequential Bonferroni correction was applied. 


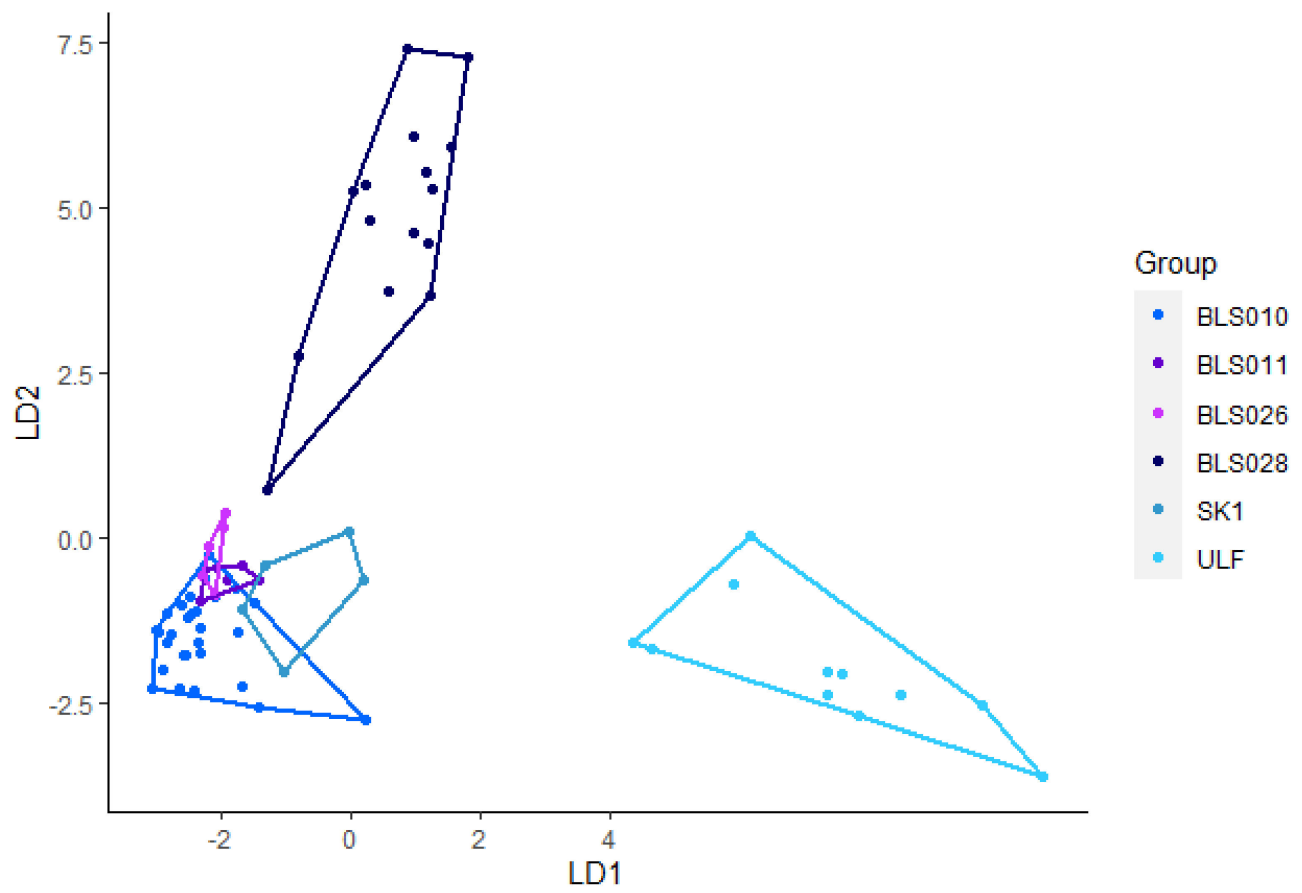

Figure 4. Linear discriminant (LD) analysis plot for individual identification of howls from Eurasian wolves with a $92 \%$ correct classification.

Table 6. Pairwise post-hoc Hotelling test for Arctic wolves with F-values, $p$-values and number of degrees of freedom (DF). Symbol ${ }^{\#}$ indicates significant $p$-values after sequential Bonferroni. n.s. indicates not significant $p$-values.

\begin{tabular}{llll}
\hline & F & $p$ & DF \\
\hline BLS010-BLS011 & 8.05 & $<0.001^{\#}$ & 7 \\
BLS010-BLS026 & 13.91 & $<0.001^{\#}$ & 7 \\
BLS010-BLS028 & 62.04 & $<0.001^{\#}$ & 7 \\
BLS010-SK1 & 58.31 & $<0.001^{\#}$ & 7 \\
BLS010-ULF & 169.04 & $<0.001^{\#}$ & 7 \\
BLS011-BLS026 & 1.56 & n.s. & 7 \\
BLS011-BLS028 & 9.21 & $<0.001^{\#}$ & 7 \\
BLS011-SK1 & 23.07 & $<0.01^{\#}$ & 7 \\
BLS011-ULF & 32.85 & $<0.001^{\#}$ & 7 \\
BLS026-BLS028 & 10.2 & $<0.001^{\#}$ & 7 \\
BLS026-SK1 & 9.61 & $<0.05$ & 7 \\
BLS026-ULF & 34.13 & $<0.001^{\#}$ & 7 \\
BLS028-SK1 & 17.44 & $<0.001^{\#}$ & 7 \\
BLS028-ULF & 37.4 & $<0.001^{\#}$ & 7 \\
SK1-ULF & 13.16 & $<0.001^{\#}$ & 7 \\
\hline
\end{tabular}

\section{Discussion}

We found that it is possible to use howls to identify individual wolves within two subspecies (Arctic and Eurasian) with high accuracy. However, although the individual identification in this study had correct classification of $80-97 \%$, noise from the surroundings made several howls unusable for extracting the fundamental frequency.

Wolves howl most actively during the months of July through October [33], whereas we recorded from late September through November and again from March to April. Future studies may benefit from collecting data in the period where wolves are more actively howling to gain larger datasets. 


\subsection{Identification of Subspecies}

The present study showed significant difference between howls from all the subspecies. For the subspecies Arctic wolves and Eurasian wolves there was a correct classification of $78 \%$ for both. This is in agreement with other studies that shows howls differed across subspecies with classifications of $87 \%$ and $81 \%$ [32,41]. For the subspecies Northwestern wolves, the correct classification accuracy was only $64 \%$. This classification could be due to most recordings being chorus howls, making individual identification difficult.

\subsection{Identifying Individuals}

It was possible to identify individual wolves within the subspecies Arctic, and Eurasian wolves based on their acoustic profile. Arctic wolves showed an overall correct classification of $95 \%$ and several wolves from both Arctic and Eurasian subspecies reached $100 \%$ correct classification. These results are in agreement with other studies showing that it is possible to identify individual wolves within subspecies based on their howls [27,36,40].

Root-Gutteridge et al. [27,40] included amplitude variables to improve individual identification, which increased their accurate classification to $100 \%$. However, amplitudes are affected by ambient noise (wind, birds, etc.), which was the case with many of the howls recorded in this study and amplitude was therefore not usable for identification of wolves. To implement the use of amplitude, meticulous collection of data is necessary. By eliciting the howling, as achieved in several other studies [32,35,42], ambient noise can be avoided in recordings and analyzing variables extracted from amplitude in addition to fundamental frequency (f0) is feasible. In addition, the surrounding terrain and distances to the wolf affects the amplitude [27]. With low quality recordings and low-cost user-friendly software, it is also possible to identify wolves, whereas more costly software such as MATLAB, may limit the access for scientists as funding and knowledge of programming is necessary to use such software [55]. Further, different studies use different software [31,40,42,43], which makes comparison of data and replication difficult [55].

\subsection{Future Use of Acoustic Monitoring}

Efficient monitoring of wolves is necessary to fulfill obligations in relation to the EU Habitats Directive and to address public concerns about the increasing populations across Europe. Acoustic monitoring is an approach that is already used for identifying different species [17-21,56,57], and over the years researchers have monitored wolves acoustically as well [25,39] and might be used to identify if there are any new wolves in an area [39]. If we want to improve the continuous monitoring of wolves in countries, such as Denmark, where the species is returning to its historic habitat, it would be advantageous to start acoustic monitoring. If we can identify known wolves on their howls, we expect to be able to identify wild wolves on their howls.

Camera traps are used today in monitoring wolves $[15,30,39]$ and both camera traps and acoustic recorders can offer a possibility for a permanent catalogue of sounds from the surroundings [30,57]. A combination of camera traps and acoustic devices could be beneficial for the research of wolves, as it can help enhance the survey area and improve detectability [30,57]. Furthermore, this combination of methods may help in understanding the interaction between wolves and humans [57]. Cameras can show the presence, type and intensity of human disturbance whereas the acoustic device can capture the noise and its intensity [57]. Having a combination of camera traps and acoustic devices can show whether wolves move away from areas with too much human activity or noise, as some animals change behavior or increase their nocturnality in areas with human activity [58]. With evolving of technologies, wolf howls recorded on mobile phones may also, in the future, be useful for monitoring wolves acoustically. This way it will be possible to involve citizens to help gain knowledge of their distribution and re-productive success. 


\section{Conclusions}

The individual identification of the captive subspecies Arctic wolves and Eurasian wolves was accurate, and subspecies could be differentiated from each other. Our results suggest that acoustic monitoring and individual identification of wild wolves is possible. This could be a valuable noninvasive and cost-effective tool to complement monitoring based on genetics analyses, camera trapping, and other methods.

Author Contributions: Conceptualization, H.L.L., S.P., N.M. and C.P.; methodology, H.L.L., S.P., N.M. and C.P.; software, H.L.L.; statistical analysis, H.L.L., C.P. and H.R.-G.; writing-original draft preparation, H.L.L.; writing — review and editing, H.L.L., S.P., C.P., N.M., H.R.-G., A.V.S. and E.R.; project administration, S.P.; funding acquisition, H.L.L. All authors have read and agreed to the published version of the manuscript.

Funding: The study was supported by the Aalborg Zoo Conservation Foundation (AZCF; grant numbers: 2020-3, 2021-7).

Institutional Review Board Statement: Ethical review and approval were granted by Nottingham Trent University's Ethical Review Board in 2010. The study complies with current Danish laws for ethical handling of animals.

Informed Consent Statement: Not applicable.

Data Availability Statement: The data presented in this study are available upon request from the corresponding author.

Acknowledgments: We wish to thank the three zoos: Givskud Zoo-Zootopia, Ree Park Safari, and Skandinavisk Dyrepark that gave permission to set up the recording device. The volunteers in the organization Ulvetrackerne; Sabrina Haaning, Paw Rasmussen, and Kim Møller for sharing their knowledge. The Danish Nature Agency for helping locating areas wild wolves.

Conflicts of Interest: The authors declare no conflict of interest.

\section{References}

1. Pagh, S. Kap 3: Ulvens biologi. In Bidrag Til Opdatering Af Forvaltningsplan for Ulv [Entry for the Update of Management Plan for Wolff; Aarhus Universitet, DCE-Nationalt Center for Miljø og Energi: Aarhus, Denmark, 2018; p. 26.

2. Boitani, L. IUCN Red List of Threatened Species: Canis lupus. IUCN Red List Threat. Species. 2018. Available online: https:/ / www.iucnredlist.org/species/3746/163508960 (accessed on 23 January 2022).

3. Svensson, L.; Wabakken, P.; Maartmann, E.; Cardoso Palacios, C.; Flagstad, Ø.; Åkesson, M. Inventering av Varg Vintern 20202021. Bestandsovervåking av Ulv Vinteren 2020-2021 [Population Monitoring of Wolf in the Winter 2020-2021]; Norsk Institutt for Naturforskning (NINA): Trondheim, Norway, 2021; ISBN 978-82-426-4783-2.

4. Olsen, K.; Sunde, P.; Vedel-Smith, C.; Hansen, M.M.; Thomsen, P.F. Statusrapport Fra Den Nationale Overvaigning Af Ulv (Canis lupus) i Danmark-2. Kvartal 2021 [Progress Report from the National Monitoring of Wolf (Canis lupus) in Denmark-2. Quarter of 2021]; Aarhus Universitet, DCE—Nationalt Center for Miljø og Energi: Aarhus, Denmark, 2021; p. 19.

5. Fuller, T.K.; Mech, L.D.; Cochrane, J.F. Wolf Population and Dynamics. In Wolves: Behavior, Ecology, and Conservation; Mech, L.D., Boitani, L., Eds.; University of Chicago Press: Chicago, IL, USA, 2003; pp. 161-191, ISBN 978-0-226-51697-4.

6. Kirilyuk, A.; Kirilyuk, V.E.; Ke, R. Long-Distance Dispersal of Wolves in the Dauria Ecoregion. Mammal Res. 2020, 65, 639-646. [CrossRef]

7. Fritts, S.H.; Stephenson, R.O.; Hayes, R.D.; Boitani, L. Wolves and Humans. In Wolves: Behavior, Ecology, and Conservation; Mech, L.D., Boitani, L., Eds.; University of Chicago Press: Chicago, IL, USA, 2003; pp. 289-316, ISBN 978-0-226-51697-4.

8. Habitats Directive: Council Directive 92/43/EEC of 21 May 1992 on the Conservation of Natural Habitats and of Wild Fauna and Flora; European Union: Brussels, Belgium, 1992; pp. 7-50.

9. Dbb-Wolf. Available online: https://www.dbb-wolf.de/home (accessed on 19 October 2021).

10. Ulveatlas [Wolf Atlas]. Available online: https:/ / www.ulveatlas.dk/ (accessed on 19 October 2021).

11. Rovdata [Predator Data]. Available online: https://rovdata.no/Ulv/Be-standsstatus.aspx (accessed on 19 October 2021).

12. Olsen, K.; Sunde, P.; Hansen, M.M.; Francis, P.; Anders, A.J. DNA-Analyser og Beskrivelse af Den Centraleuropæiske Ulvebestand, Herunder Identifikation af Ulve og Ulvehybrider [DNA-Analyses and Description of the Central European Wolf Population, Including Wolves and Wolfhybrids]; DCE—Nationalt Center for Miljø og Energi og Naturhistorisk Museum Aarhus: Aarhus, Denmark, 2019; p. 15.

13. Olsen, K.; Sunde, P.; Vede-Smith, C.; Hansen, M.M.; Thomsen, P.F. Statusrapport fra den Nationale Overvågning af Ulv (Canis lupus) $i$ Danmark-3. Kvartal 2020 [Progress Report from the National Monitoring of Wolf (Canis lupus) in Denmark-3. Quarter of 2020]; Aarhus Universitet, DCE—Nationalt Center for Miljø og Energi: Aarhus, Denmark, 2020; p. 19. 
14. Breitenmoser, U.; Breitenmoser-Würsten, C.; von Arx, M.; Zimmermann, F.; Ryser, A.; Angst, C.; Molinari-Jobin, A.; Molinari, P.; Linell, J.; Siegenthaler, A.; et al. Guidelines for the Monitoring of Lynx. KORA Ber. 2006, 33, 17-26.

15. Sunde, P.; Olsen, K. Ulve (Canis lupus) i Danmark 2012-2017: Oversigt og Analyse af Tilgængelig Bestandsinformation [Wolves (Canis lupus) in Denmark 2012-2017: Overview and Analysis of Available Population Information]; Aarhus Universitet, DCE-Nationalt Center for Miljø og Energi: Roskilde, Denmark, 2018; pp. 15-16.

16. Mankin, R.W.; Hagstrum, D.W.; Smith, M.T.; Roda, A.L.; Kairo, M.T.K. Perspective and Promise: A Century of Insect Acoustic Detection and Monitoring. Am. Entomol. 2011, 57, 30-44. [CrossRef]

17. Elmeros, M.; Fjederholt, E.T.; Baagøe, H.J. Overvågning Af Flagermus På Bornholm i 2018 [Monitoring of Bats on Bornholm 2018]; DCE-Nationalt Center for Miljø og Energi: Aarhus, Denmark, 2018.

18. Fjederholt, E.T.; Johansen, T.W.; Dahl Møller, J.; Christensen, M.; Baagøe, H.J. NOVANA-Overvågning Af Flagermus i 2020 [NOVANA-Monitoring of Bats in 2020]; Aarhus Universitet, DCE-Nationalt Center for Miljø og Energi: Aarhus, Denmark, 2020.

19. Stastny, J.; Munk, M.; Juranek, L. Automatic Bird Species Recognition Based on Birds Vocalization. EURASIP J. Audio Speech Music Process. 2018, 2018, 19. [CrossRef]

20. Moore, S.E.; Stafford, K.M.; Mellinger, D.K.; Hildebrand, J.A. Listening for Large Whales in the Offshore Waters of Alaska. BioScience 2006, 56, 49-55. [CrossRef]

21. Brown, J.C.; Smaragdis, P.; Nousek-McGregor, A. Automatic Identification of Individual Killer Whales. J. Acoust. Soc. Am. 2010, 128, EL93-EL98. [CrossRef]

22. Rusin, I.Y.; Volodin, I.A.; Sitnikova, E.F.; Litvinov, M.N.; Andronova, R.S.; Volodina, E.V. Roaring Dynamics in Rutting Male Red Deer Cervus elaphus from Five Russian Populations. Russ. J. Theriol. 2021, 20, 44-58. [CrossRef]

23. Volodina, E.V.; Volodin, I.A.; Frey, R. Male Impala (Aepyceros melampus) Vocal Activity throughout the Rutting Period in Namibia: Daily and Hourly Patterns. Afr. J. Ecol. 2021, 60, 95-99. [CrossRef]

24. Wrege, P.H.; Rowland, E.D.; Keen, S.; Shiu, Y. Acoustic Monitoring for Conservation in Tropical Forests: Examples from Forest Elephants. Methods Ecol. Evol. 2017, 8, 1292-1301. [CrossRef]

25. Papin, M.; Pichenot, J.; Guérold, F.; Germain, E. Acoustic Localization at Large Scales: A Promising Method for Grey Wolf Monitoring. Front. Zool. 2018, 15, 11. [CrossRef]

26. Joslin, P.W.B. Movements and Home Sites of Timber Wolves in Algonquin Park. Am. Zool. 1967, 7, 279-288. [CrossRef]

27. Root-Gutteridge, H.; Bencsik, M.; Chebli, M.; Gentle, L.K.; Terrell-Nield, C.; Bourit, A.; Yarnell, R.W. Identifying Individual Wild Eastern Grey Wolves (Canis lupus lycaon) Using Fundamental Frequency and Amplitude of Howls. Bioacoustics 2014, $23,55-66$. [CrossRef]

28. Suter, S.M.; Giordano, M.; Nietlispach, S.; Apollonio, M.; Passilongo, D. Non-Invasive Acoustic Detection of Wolves. Bioacoustics 2017, 26, 237-248. [CrossRef]

29. Whytock, R.C.; Christie, J. Solo: An Open Source, Customizable and Inexpensive Audio Recorder for Bioacoustic Research. Methods Ecol. Evol. 2017, 8, 308-312. [CrossRef]

30. Garland, L.; Crosby, A.; Hedley, R.; Boutin, S.; Bayne, E. Acoustic vs. Photographic Monitoring of Gray Wolves (Canis lupus): A Methodological Comparison of Two Passive Monitoring Techniques. Can. J. Zool. 2020, 98, 219-228. [CrossRef]

31. Passilongo, D.; Mattioli, L.; Bassi, E.; Szabó, L.; Apollonio, M. Visualizing Sound: Counting Wolves by Using a Spectral View of the Chorus Howling. Front. Zool. 2015, 12, 22. [CrossRef]

32. Hennelly, L.; Habib, B.; Root-Gutteridge, H.; Palacios, V.; Passilongo, D. Howl Variation across Himalayan, North African, Indian, and Holarctic Wolf Clades: Tracing Divergence in the World's Oldest Wolf Lineages Using Acoustics. Curr. Zool. 2017, 63, 341-348. [CrossRef]

33. Harrington, F.H.; Mech, L.D. Wolf Howling and Its Role in Territory Maintenance. Behaviour 1979, 68, 207-249. [CrossRef]

34. Mitchell, B.R.; Makagon, M.M.; Jaeger, M.M.; Barrett, R.H. Information Content of Coyote Barks and Howls. Bioacoustics 2006, 15, 289-314. [CrossRef]

35. Nowak, S.; Jędrzejewski, W.; Schmidt, K.; Theuerkauf, J.; Mysłajek, R.W.; Jędrzejewska, B. Howling Activity of Free-Ranging Wolves (Canis lupus) in the Białowieża Primeval Forest and the Western Beskidy Mountains (Poland). J. Ethol. 2007, 25, 231-237. [CrossRef]

36. Palacios, V.; Font, E.; Márquez, R. Iberian Wolf Howls: Acoustic Structure, Individual Variation, and a Comparison with North American Populations. J. Mammal. 2007, 88, 606-613. [CrossRef]

37. Theberge, J.B.; False, J.B. Howling as a Means of Communication in Timber Wolves. Am. Zool. 1967, 7, 331-338. [CrossRef]

38. Tooze, Z.J.; Harrington, F.H.; Fentress, J.C. Individually Distinct Vocalizations in Timber Wolves, Canis lupus. Anim. Behav. 1990, 40, 723-730. [CrossRef]

39. Sadhukhan, S.; Root-Gutteridge, H.; Habib, B. Identifying Unknown Indian Wolves by Their Distinctive Howls: Its Potential as a Non-Invasive Survey Method. Sci. Rep. 2021, 11, 7309. [CrossRef]

40. Root-Gutteridge, H.; Bencsik, M.; Chebli, M.; Gentle, L.K.; Terrell-Nield, C.; Bourit, A.; Yarnell, R.W. Improving Individual Identification in Captive Eastern Grey Wolves (Canis lupus lycaon) Using the Time Course of Howl Amplitudes. Bioacoustics 2014, 23, 39-53. [CrossRef]

41. Kershenbaum, A.; Root-Gutteridge, H.; Habib, B.; Koler-Matznick, J.; Mitchell, B.; Palacios, V.; Waller, S. Disentangling Canid Howls across Multiple Species and Subspecies: Structure in a Complex Communication Channel. Behav. Process. 2016, 124, 149-157. [CrossRef] 
42. Zaccaroni, M.; Passilongo, D.; Buccianti, A.; Dessì-Fulgheri, F.; Facchini, C.; Gazzola, A.; Maggini, I.; Apollonio, M. Group Specific Vocal Signature in Free-Ranging Wolf Packs. Ethol. Ecol. Evol. 2012, 24, 322-331. [CrossRef]

43. Randler, C.; Kalb, N. Distance and Size Matters: A Comparison of Six Wildlife Camera Traps and Their Usefulness for Wild Birds. Ecol. Evol. 2018, 8, 7151-7163. [CrossRef]

44. Zimen, E. On the Regulation of Pack Size in Wolves. Z. Tierphysiol. 2010, 40, 300-341. [CrossRef]

45. Walker, K.M.; Gonzalez, R.; Kang, J.Z.; McDermott, J.H.; King, A.J. Across-Species Differences in Pitch Perception Are Consistent with Differences in Cochlear Filtering. eLife 2019, 8, e41626. [CrossRef]

46. De Cheveigné, A.; Kawahara, H. YIN, a Fundamental Frequency Estimator for Speech and Music. J. Acoust. Soc. Am. 2002, 111, 1917-1930. [CrossRef] [PubMed]

47. Audacity Team. Audacity ${ }^{\circledR}$. Version 2.4.2. Available online: http://audacityteam.org/ (accessed on 16 November 2020).

48. Boersma, P.; Weenink, D. Praat: Doing Phonetics by Computer [Computer Program]. Available online: http://www.praat.org/ (accessed on 16 February 2021).

49. Mathworks Inc. MATLAB, Version 9.9.0.1592791 (R2020b) Update 5; Mathworks: Natick, MA, USA, 2020.

50. Watson, S.K.; Townsend, S.W.; Range, F. Wolf Howls Encode Both Sender- and Context-Specific Information. Anim. Behav. 2018, 145, 59-66. [CrossRef]

51. Sueur, J. Sound Analysis and Synthesis with R, 1st ed.; Use R! Springer International Publishing: Cham, Switzerland, 2018; ISBN 978-3-319-77647-7.

52. Rstudio Team. RStudio: Integrated Development Environment for R; Rstudio: Boston, MA, USA, 2021.

53. Sueur, J.; Aubin, T.; Simonis, C. Seewave, a Free Modular Tool for Sound Analysis and Synthesis. Bioacoustics 2008, 18, $213-226$. [CrossRef]

54. Rice, W.R. Analyzing Tables of Statistical Tests. Evolution 1989, 43, 223-225. [CrossRef]

55. Hull, C.; McCombe, C.; Dassow, A. Acoustic Identification of Wild Gray Wolves, Canis lupus, Using Low Quality Recordings. Am. J. Undergrad. Res. 2020, 16, 41-49. [CrossRef]

56. Ciira, W.M. Cost Effective Acoustic Monitoring of Bird Species. In Proceedings of the Interspeech, San Francisco, CA, USA, 8 September 2016; pp. 2617-2620.

57. Buxton, R.T.; Lendrum, P.E.; Crooks, K.R.; Wittemyer, G. Pairing Camera Traps and Acoustic Recorders to Monitor the Ecological Impact of Human Disturbance. Glob. Ecol. Conserv. 2018, 16, e00493. [CrossRef]

58. Gaynor, K.M.; Hojnowski, C.E.; Carter, N.H.; Brashares, J.S. The Influence of Human Disturbance on Wildlife Nocturnality. Science 2018, 360, 1232-1235. [CrossRef] 